\title{
DeterminaçÃo do TEMPo NECESSÁRIO PARA OXIDAÇÃo DA MATÉRIA ORGÂNICA FACILMENTE BIODEGRADÁVEL EM REATOR SEQÜENCIAL EM BATELADA (RSB) COM ENCHIMENTO ESTÁTICO
}

\author{
DETERMINATION OF THE TIME NEEDED TO OXIDIZE THE EASILY \\ BIODEGRADABLE ORGANIC MATTER IN A SEQUENTIAL BATCH REACTOR (SBR) \\ WITH STATIC FILLING
}

ALTEMAR VILAR DOS SANTOS

Doutor em Recursos Hídricos e Saneamento Ambiental pelo Instituto de Pesquisas Hidráulicas da Universidade Federal do Rio Grande do Sul. Professor do Centro Federal de Educação Tecnológica da Bahia

\section{LUIZ FERNANDO DE ABREU CYBIS}

Ph.D. em Engenharia Sanitária e Ambiental pela The University of Leeds e professor do Instituto de Pesquisas Hidráulicas da Universidade Federal do Rio Grande do Sul

\section{GINo Roberto GEHLING}

Doutor em Engenharia Ambiental pela Universitat Politécnica de Catalunya. Professor do Instituto de Pesquisas Hidráulicas da Universidade Federal do Rio Grande do Sul

\author{
Recebido: 05/08/05 Aceito: 21/02/05
}

\begin{abstract}
RESUMO
Este trabalho teve como objetivo propor uma metodologia para determinar o tempo de aeração no RSB necessário para oxidação da matéria orgânica facilmente biodegradável. A metodologia proposta consiste em aplicar o conceito de equaçôes de diferenças não-lineares nos dados de taxa de consumo de oxigênio (TCO). Os dados experimentais utilizados no trabalho foram obtidos num RSB em escala de bancada. As médias do tempo para oxidação da matéria orgânica facilmente biodegradável foram $0,83,0,83,1,17$ e 1,54 horas para as idades do lodo de 30, 20, 10 e 5 dias, respectivamente. Estes valores se mostraram semelhantes aos valores recomendados na literatura de lodos ativados. A metodologia ora proposta é de fácil aplicação aos dados de TCO e proporciona uma contribuição na busca de minimizar os custos operacionais do RSB.
\end{abstract}

PALAVRAS-CHAVE: Reator seqüencial em batelada, RSB, taxa de consumo de oxigênio, tempo de reação aeróbia, esgoto sanitário.

\begin{abstract}
The purpose of this study was to propose a method to determine the aeration time needed in the SBR for oxidation of easily biodegradable organic matter. The method proposed consists of applying the concept of equations of non-linear differences to the data of oxygen utilization rate (OUR) The experimental data used in the study were obtained from a bench scale SBR. The mean times required for oxidation of easily degradable organic matter were $0.83,0.83,1.17$ and 1.54 hours for sludges aged 30, 20, 10 and 5 days, respectively. These values were similar to the values recommended in the literature on activated sludges. The method proposed here is easy to apply to the OUR data and provides a contribution in seeking to minimize the operating costs of the SBR.
\end{abstract}

KEYWORDS: Sequencing batch reactor, SBR, oxygen uptake rate, react period, wastewater.

\section{INTRODUÇÃO}

A versão original do sistema de lodos ativados funcionava em batelada. A criação deste sistema é atribuída a Arden e Lockett, no ano de 1914. Apesar da simplicidade conceitual do processo em batelada, este foi logo substituído pelo processo contínuo em função da necessidade de redução de mão-de-obra para operação. Em função das limitações téc- nicas na época da invenção do processo de lodos ativados para estabelecer a automação do ciclo operacional do RSB, os sistemas contínuos se proliferaram e passaram a ser o processo mais adotado no tratamento de esgoto. Nos anos 80 do séculoXX, o desenvolvimento tecnológico alavancou o emprego dos sistemas de lodos ativados em batelada em função da mecanização seguida da automação deste processo de tratamento de esgoto. Apesar do avanço na operação do RSB, a definição do ciclo operacional continua sendo fundamentada na experiência de alguns pesquisadores e em dados obtidos de experiências bem sucedidas nas estações em escala real. A definição do ciclo operacional do reator seqüencial em batelada se constitui numa tarefa empírica. A partir deste cenário, o presente trabalho teve como objetivo propor uma metodologia para estabelecer o tempo da fase aeróbia para 
oxidar a matéria orgânica facilmente biodegradável no RSB.

\section{MATERIAIS E MÉTODOS}

O trabalho experimental foi desenvolvido em escala de bancada no laboratório de saneamento ambientaldo IPH/UFRGS. A sala usada para acomodar o experimento era climatizada por dois condicionadores de ar para manter a temperatura em $20^{\circ} \mathrm{C}$. O reator seqüencial em batelada utilizado foi confeccionado em forma cilíndrica com chapas de acrílico. A alimentação com esgoto, a retirada do efluente final e o descarte do lodo de excesso eram realizados por bombas dosadoras do tipo peristálticas Masterflex modelo 7518-10. O descarte do lodo de excesso ocorria em cada batelada antes do início da fase de sedimentação. O fornecimento de ar era feito através de quatro pedras porosas ligadas a uma bomba de aquário marca Big Air modelo A420 com ajuste manual da vazão de ar. Para evitar zonas mortas e garantir uma mistura homogênea, o RSB estava equipado com sistema de agitação constituído por um eixo com hélice acoplado a um agitador da marca Motron modelo MR910-60. Ao longo da pesquisa, os volumes de enchimento, trabalho e descarga de efluente foram 4, 9 e $4 \mathrm{~L}$ por ciclo, respectivamente. Eram realizados três ciclos operacionais por dia com duração de oito horas. Cada ciclo era composto das seguintes fases: enchimento estático (uma hora), reação aeróbia (quatro horas), sedimentação (uma hora), esvaziamento (quinze minutos) e descanso (uma hora e quarenta e cinco minutos). O controle do tempo de cada fase dos ciclos era feito por um microcomputador ligado às bombas peristálticas, à bomba de aeração e ao sistema de agitação. $\mathrm{O}$ esgoto utilizado para alimentar o reator era coletado na Estação de Tratamento de Esgoto - ETE Esmeralda, pertencente ao Departamento Municipal de Água e Esgotos - DMAE de Porto Alegre. Antes de ser utilizado como substrato, a DQO do esgoto era corrigida para $300 \mathrm{mg} / \mathrm{L}$. Quando a demanda química de oxigênio superava este valor, o esgoto era diluído com água sem cloro; caso contrário, era adicionado etanol como fonte de carbono. Após esta fase, o esgoto era armazenado num balde com tampa e colocado numa geladeira para alimentar o RSB. Na tampa foi instalado um agitador Motron modelo MR910-60 acoplado num eixo com hélice. No decorrer da pesquisa foram utilizadas as ida- des do lodo de 30, 20, 10 e 5 dias. As concentrações médias de sólidos suspensos voláteis no reator obtidas para esta seqüência de idade do lodo foram 3.444, 2.024, 1.610 e $679 \mathrm{mg} / \mathrm{L}$, respectivamente. O lodo utilizado para inoculação era de um RSB em escala piloto montado na ETE Esmeralda para reduzir o tempo de aclimatação da biomassa matação, era calculado o somatório das massas de matéria orgânica oxidada, convertida em lodo e efluente. Quando a razão entre este somatório e a massa de matéria orgânica afluente (coeficiente de retorno) atingia valores entre 0,80 e 1,20, era iniciada a coleta de dados. Para garantir o consumo de oxigênio apenas por bactérias heterotróficas, foram aplicados $10 \mathrm{~mL}$ de tiouréia de concentração $2000 \mathrm{mg} / \mathrm{L}$ todos os dias. A taxa de consumo de oxigênio (TCO) foi obtida através de um sistema de aquisição de dados on line para oxigênio dissolvido ligado no microcomputador encarregado de controlar os ciclos operacionais. As concentrações de oxigênio dissolvido foram determinadas segundo o Standard Methods for the Examination of Water and Wastewater (1995).

A metodologia proposta para definir o tempo de aeração necessário para oxidar a matéria orgânica facilmente biodegradável afluente é fundamentada na estabilidade de equações de diferenças não-lineares. O primeiro passo para analisar os dados de TCO é colocá-los na ordem crescente dos valores. A seqüiência obtida é $\mathrm{TCO}_{0}, \mathrm{TCO}_{1}, \ldots, \mathrm{TCO}_{\mathrm{n}-1}$, $\mathrm{TCO}_{\mathrm{n}}$, sendo $\mathrm{n}$ um número pertencente ao conjunto dos números naturais. No sistema cartesiano, considerando os valores de $\mathrm{TCO}_{\mathrm{n}}$ no eixo das abscissas e $\mathrm{TCO}_{n+1}$ no eixo das ordenadas se obtém a curva $\mathrm{TCO}_{\mathrm{n}+1}=\mathrm{f}\left(\mathrm{TCO}_{\mathrm{n}}\right)$ (Figura 1) a partir dos pontos $\left(\mathrm{TCO}_{\mathrm{n}}, \mathrm{TCO}_{\mathrm{n}+1}\right)$. A determinação da TCO que define o fim da oxidação da matéria orgânica facilmente biodegradável pode ser realizada de forma analítica ou gráfica. Da primeira forma, a função polinomial que se ajusta à curva obtida a partir dos pontos $\left(\mathrm{TCO}_{\mathrm{n}}\right.$, $\mathrm{TCO}_{n+1}$ ) é igualada à função $\mathrm{f}\left(\mathrm{TCO}_{\mathrm{n}}\right)=\mathrm{TCO}_{\mathrm{n}}$ que define a bissetriz do gráfico. $\mathrm{O}$ resultado desta igualdade é um polinômio do segundo grau. A maior raiz deste polinômio é a TCO que estabelece o fim da oxidação da matéria orgânica facilmente biodegradável. O método gráfico consiste na determinação do maior valor da TCO a partir da interseção do polinômio do $2^{\circ}$ grau com a bissetriz do gráfico de acordo com a Figura 1. O tem- po gasto para ocorrer a degradação dos compostos orgânicos facilmente biodegradáveis é determinado no gráfico da TCO versus tempo da forma apresentada na Figura 2.

A partir dos dados da taxa de consumo de oxigênio foram estabelecidas as equações de diferenças não-lineares e desenvolvido o estudo analítico e gráfico descrito nos resultados.

\section{RESULTADOS}

A taxa de consumo de oxigênio é uma curva contínua ao longo do tempo. A determinação deste parâmetro incide sobre as limitações da concentração máxima de oxigênio dissolvido que pode ser obtida no licor misto. Em função deste cenário, é necessário determinar várias taxas de consumo de oxigênio ao longo da batelada. Tal procedimento gera a discretização dos valores obtidos para taxa de consumo de oxigênio (Figuras 3, 4, 5 e 6).

A partir dos gráficos de $\mathrm{TCO}_{\mathrm{n}+1} \times \mathrm{TCO}_{\mathrm{n}}$ (Figuras 3, 4, 5 e 6), constata-se que a taxa de variação dos dados não é constante. A função que relaciona $\mathrm{TCO}_{\mathrm{n}}$ e $\mathrm{TCO}_{\mathrm{n}+1}$ do tipo

$\mathrm{TCO}_{\mathrm{n}+1}=\mathrm{f}\left(\mathrm{TCO}_{\mathrm{n}}\right)$

é uma equação de diferenças não-linear de primeira ordem (Bassanezi, 2002), onde fé uma combinação não linear de $\mathrm{TCO}_{\mathrm{n}}$. Traçando uma bissetriz $\mathrm{TCO}_{\mathrm{n}+1}^{\mathrm{n}}=\mathrm{TCO}_{\mathrm{n}}$ no gráfico de $\mathrm{TCO}_{n+1}{ }^{\mathrm{x}} \mathrm{TCO}_{\mathrm{n}}$, observa-se que ocorre pelo menos uma interseção do gráfico de f com a bissetriz (Figuras 3, 4, 5 e 6). Se houver mais de uma interseção, o maior valor da TCO é um ponto instável e o menor é um ponto assintoticamente estável (Bassanezi, 2002).

A tendência de comportamento dos pontos plotados no gráfico de $\mathrm{TCO}_{n+1} \mathrm{xTCO}_{\mathrm{n}}$ sugere um ajuste polinomial para os dados. Tal ajuste relaciona os dados experimentais a um polinômio do $2^{\circ}$ grau.

Para análise da TCO, a interseção de maior interesse entre o gráfico de fe a bissetriz é a taxa de consumo de oxigênio de maior valor. Este ponto deve caracterizar o fim da oxidação da matéria orgânica facilmente biodegradável definida por Marais e Ekama (1977). Quando existir duas interseçōes, o menor valor estabelece a TCO referente ao decaimento endógeno, uma vez que há uma convergência dos valores da taxa de consumo de oxigênio para esse valor. Nos gráficos da 


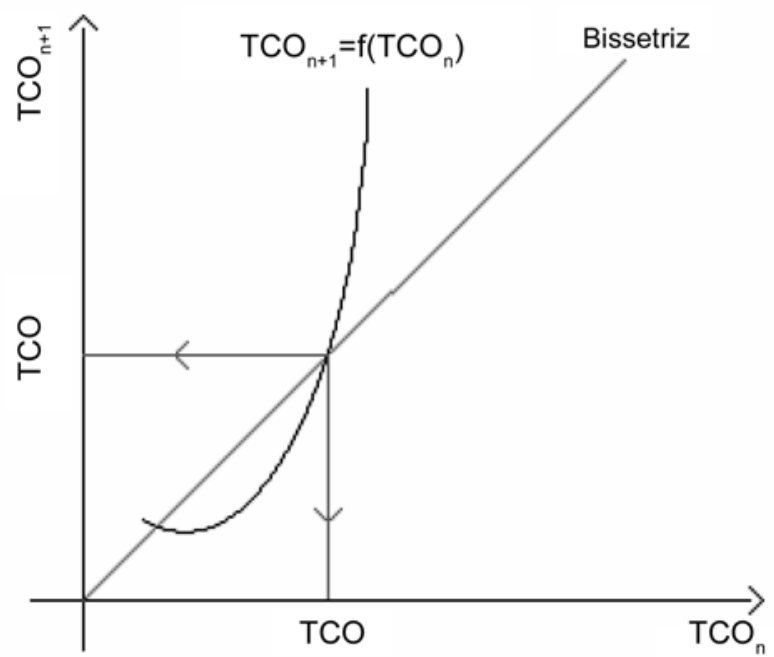

Figura I - Determinação da TCO que define o fim da degradação da matéria orgânica facilmente biodegradável no gráfico de $\mathrm{TCO}_{n+1} \times \mathrm{TCO}_{n}$.

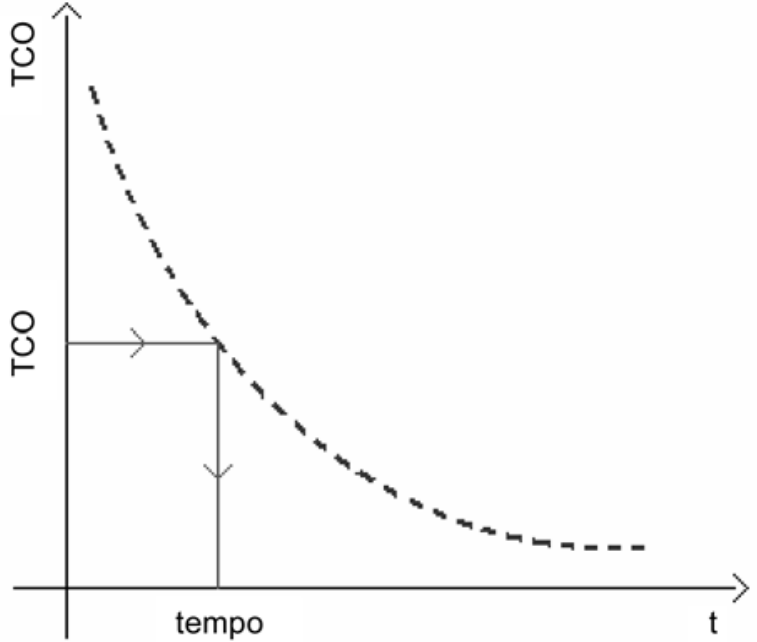

Figura 2 - Determinação do tempo necessário para degradação da matéria orgânica facilmente biodegradável no gráfico de TCOxt
TCO ao longo do tempo, observa-se que a assíntota horizontal define também a velocidade de degradação da matéria orgânica liberada no decaimento endógeno. Nas Figuras 3, 4, 5 e 6, constata-se que o tempo de quatro horas de aeração é muito elevado para remoção da matéria orgânica biodegradável. Além disso, não existe nenhuma particularidade nos gráficos da TCOxtempo capaz de caracterizar o fim da oxidação da matéria orgânica facilmente biodegradável. Em função desta situação, constata-se a necessidade de uma descrição mais refinada do comportamento da taxa de consumo de oxigênio.

A partir da metodologia proposta foram determinados os valores da TCO que definem o fim da oxidação da matéria orgânica facilmente biodegradável. Nos gráficos de TCOxt foram determinados os tempos necessários para degradação dos compostos orgânicos facilmente biodegradáveis. Os valores obtidos estão apresentados na Tabela 1 .

Em função dos resultados obtidos, constata-se que o emprego da metodologia ora proposta pode contribuir para otimizar a utilização de lodos ativados em batelada no tratamento de água residuária. A seguir serão discutidos os resultados obtidos, a metodologia proposta e sua aplicação.

\section{DISCUSSÃO}

Uma análise mais criteriosa dos gráficos de $\mathrm{TCO}_{\mathrm{n}+1} \times \mathrm{TCO}_{\mathrm{n}}$ mostra que as variações de $\mathrm{TCO}_{\mathrm{n}+1}$ não obedecem a uma constante. As tangentes às curvas obtidas do ajuste polinomial decrescem ao longo da batelada. Constata-se que estas curvas podem ser divididas em dois trechos. A primeira parte das curvas corresponde ao trecho entre o início da batelada e a TCO que define o fim da oxidação dos compostos orgânicos facilmente biodegradáveis. Neste segmento da curva há disponibilidade de matéria orgânica facilmente biodegradável no reator. É importante ressaltar que o $\Delta \mathrm{TCO}_{\mathrm{n}+1}$ é decrescente como a matéria orgânica disponível para o metabolismo bacteriano. $\mathrm{Na}$ interseção do gráfico de $\mathrm{f}\left(\mathrm{TCO}_{\mathrm{n}}\right)$ com a bissetriz TCO $_{n+1}=\operatorname{TCO}_{n}$ (Figura 1) é possível atribuir o fim da disponibilidade de matéria orgânica facilmente biodegradável. Este fato se deve a maior redução do $\Delta \mathrm{TCO}_{\mathrm{n}+1}$ em relação a redução do $\Delta \mathrm{TCO}_{\mathrm{n}}$. Este ponto revela que a capacidade de oxidação da biomassa presente no reator está acima da disponibilidade de matéria orgânica no reator. Do ponto de vista matemático, tal valor da TCO corresponde a um ponto de equilíbrio instável da equação de diferenças nãolineares. Em relação à cinética do processo de degradação da matéria orgânica, a velocidade de variação da TCO tende para zero. A partir deste ponto, o consumo de oxigênio fica limitado à oxidação de compostos orgânicos de degradação lenta. Em relação ao processo de lodos ativados, este ponto é uma separação entre matéria orgânica de fácil e de difícil degradação. Quando a curva obtida do ajuste polinomial intercepta a bissetriz em dois pontos, o segundo ponto indica a existência de convergência dos dados experimentais. A TCO deste ponto é assintoticamente estável e pode ser observada nos gráficos de TCOxt. Se houver apenas uma interseção entre a curva obtida do ajuste polinomial com a bissetriz, constata-se que a fração de matéria orgânica de degradação lenta presente no reator é elevada. Além disso, é possível que a biomassa do reator não tenha desenvolvido enzimas com capacidade para hidrolisar os compostos orgânicos de degradação lenta.

Nas Figuras 3, 4, 5 e 6, predominam gráficos de $\mathrm{TCO}_{\mathrm{n}+1} \times \mathrm{TCO}_{\mathrm{n}}$ que interceptam a bissetriz em dois pontos. É possível que este comportamento esteja ligado ao fato do sistema ter alcançado um pseudo-estado estacionário e da adaptação da biomassa ao substrato. Nos demais casos, é possível que as variaçôes intrínsecas da composição do esgoto doméstico usado como substrato tenha influenciado o comportamento da velocidade dos processos biológicos da biomassa.

A análise da variação da TCO em relação à própria TCO estabelece a possibilidade de avaliar a velocidade de oxidação da matéria orgânica desvinculada do fator tempo, uma vez que não existe uma singularidade no gráfico TCOxt capaz de identificar o fim da oxidação da matéria orgânica facilmente biodegradável. Além disso, é possível constatar em função da velocidade do catabolismo bacteriano a presença de compostos orgânicos de degradação lenta. 
a) PRIMEIRA COLETA DE DADOS
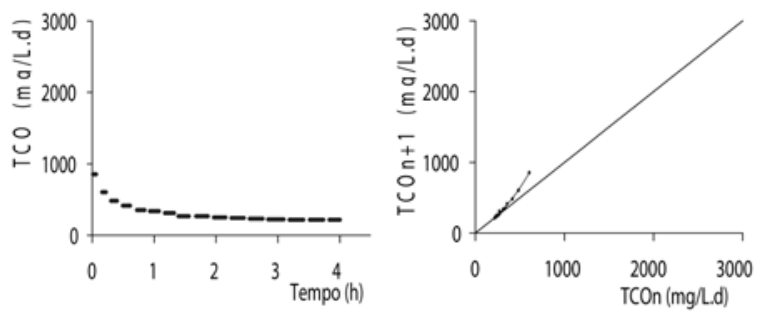

c) TERCEIRA COLETA DE DADOS
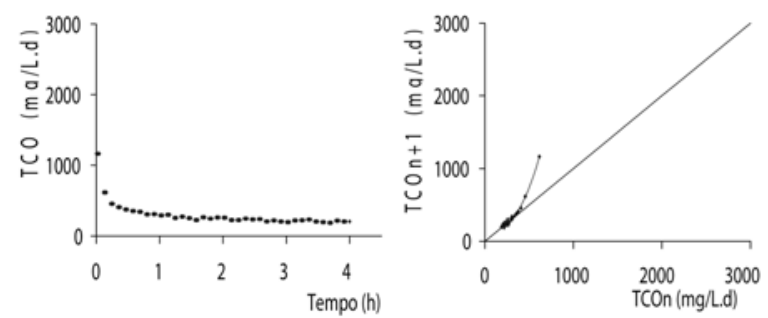

e) QUINTA COLETA DE DADOS
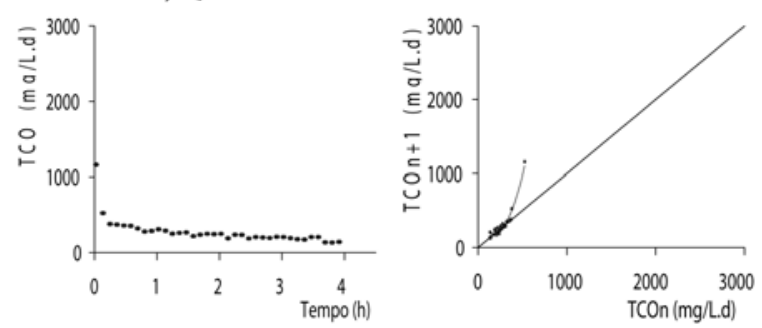

g) SÉTIMA COLETA DE DADOS
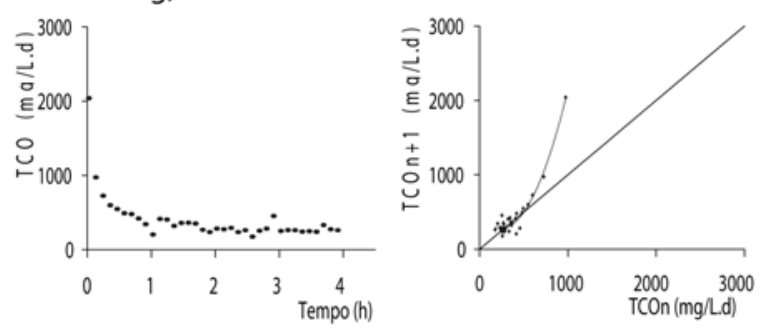

i) NONA COLETA DE DADOS
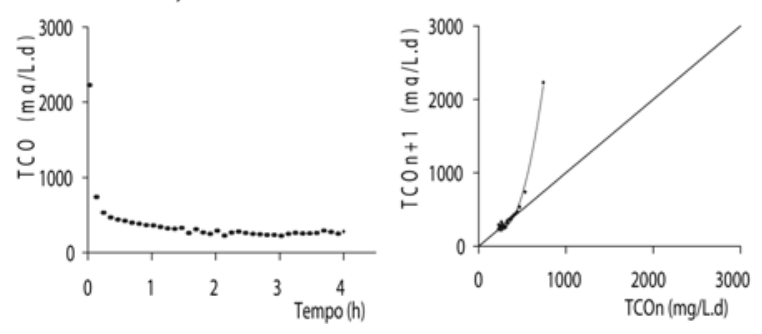

b) SEGUNDA COLETA DE DADOS
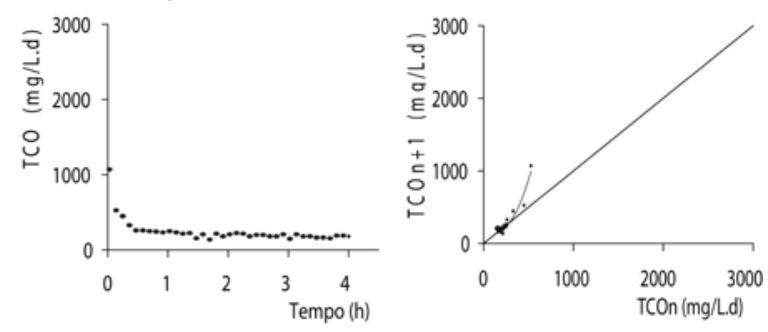

d) QUARTA COLETA DE DADOS
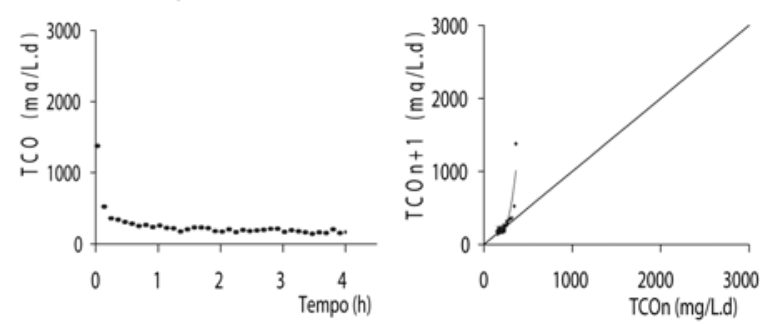

f) SEXTA COLETA DE DADOS
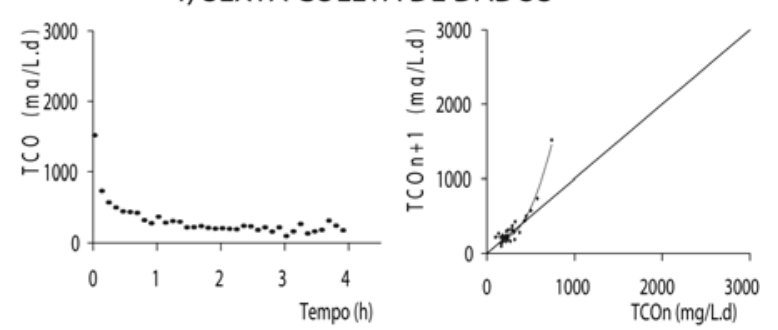

h) OITAVA COLETA DE DADOS
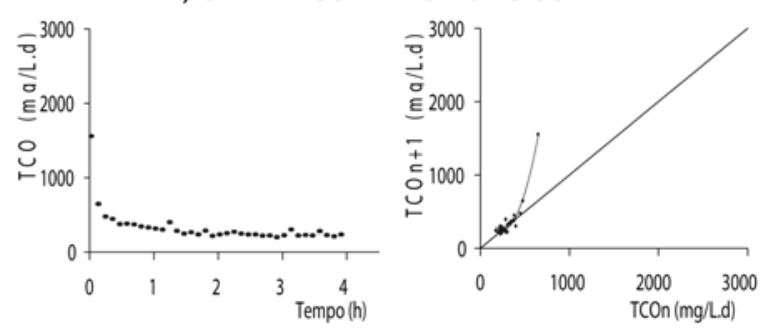

j) DÉCIMA COLETA DE DADOS
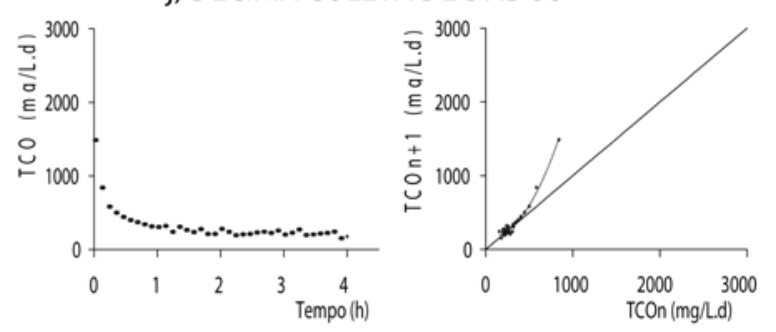

Figura 3 - Taxas de consumo de oxigênio dissolvido e gráficos de $\mathrm{TCO}_{n+1} \times \mathrm{TCO}_{n}$ obtidos na idade de lodo de 30 dias 
a) PRIMEIRA COLETA DE DADOS
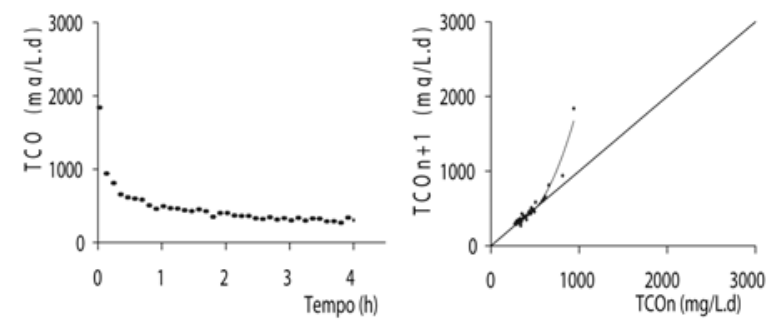

c) TERCEIRA COLETA DE DADOS
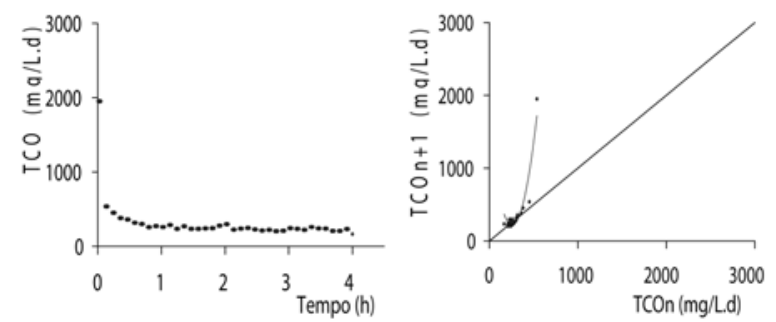

e) QUINTA COLETA DE DADOS
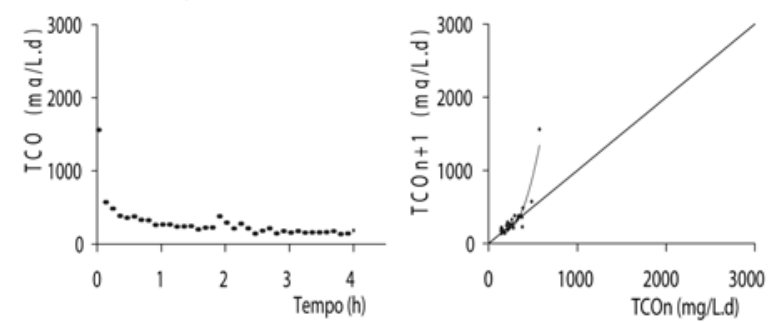

g) SÉTIMA COLETA DE DADOS
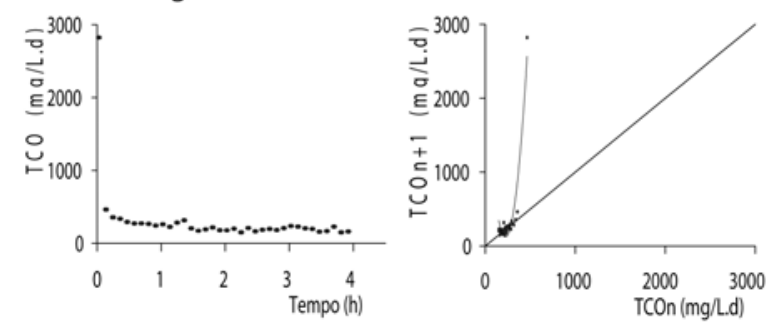

i) NONA COLETA DE DADOS
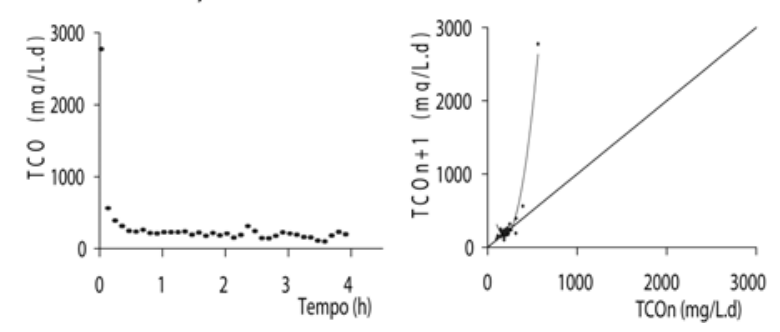

b) SEGUNDA COLETA DE DADOS
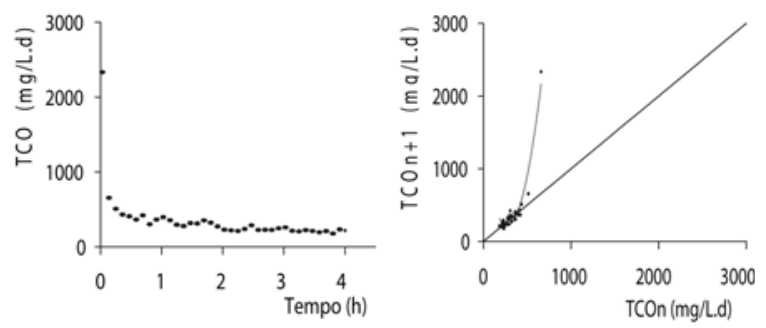

d) QUARTA COLETA DE DADOS
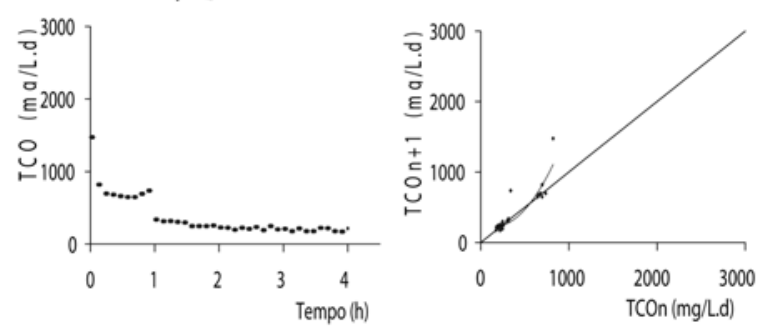

f) SEXTA COLETA DE DADOS
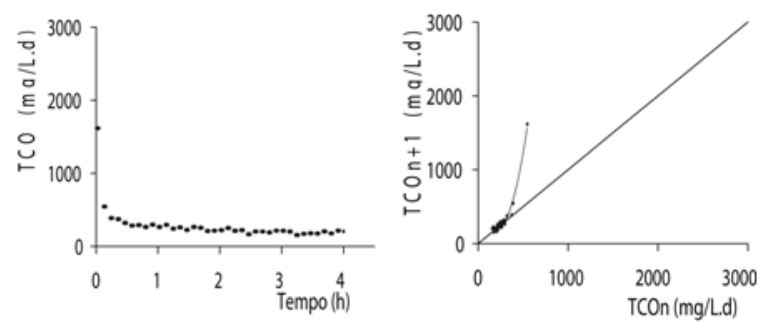

h) OITAVA COLETA DE DADOS
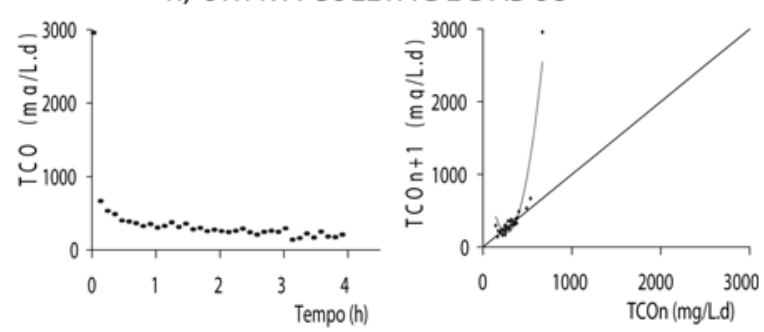

j) DÉCIMA COLETA DE DADOS
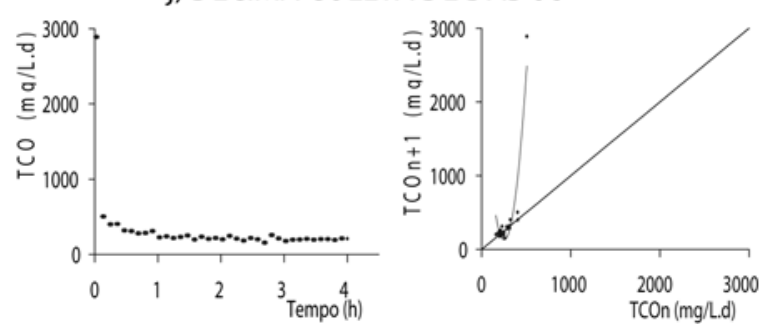

Figura 4 - Taxas de consumo de oxigênio dissolvido e gráficos de $\mathrm{TCO}_{n+1} \times \mathrm{TCO}_{n}$ obtidos na idade de lodo de 20 dias 
a) PRIMEIRA COLETA DE DADOS
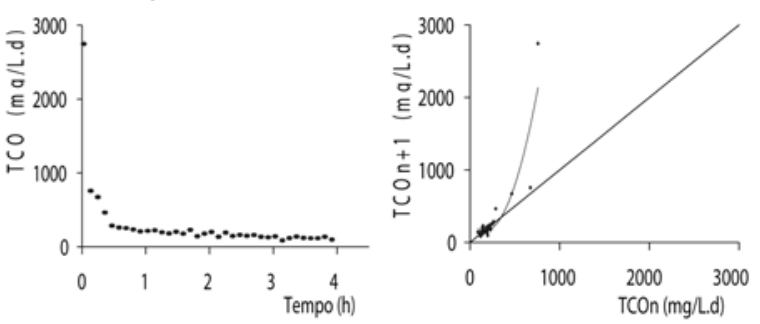

c) TERCEIRA COLETA DE DADOS
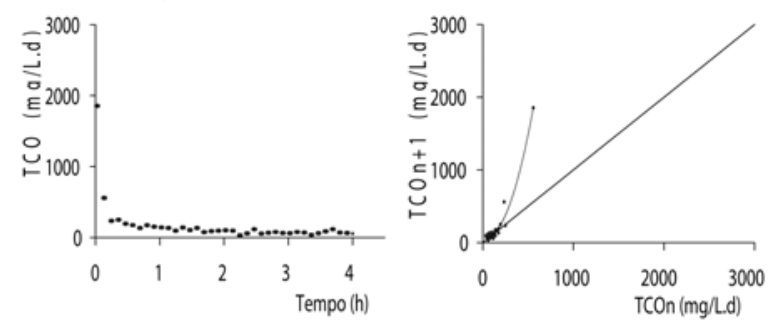

e) QUINTA COLETA DE DADOS
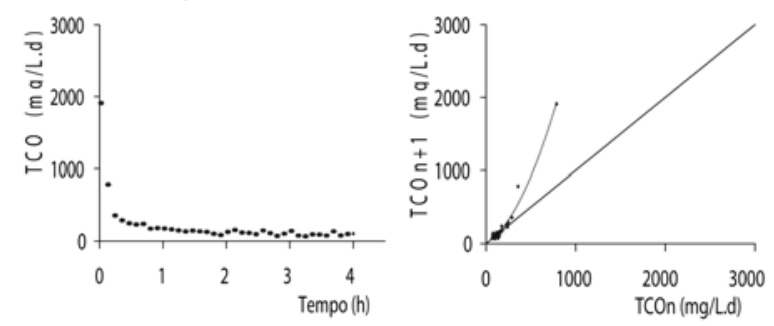

g) SÉTIMA COLETA DE DADOS
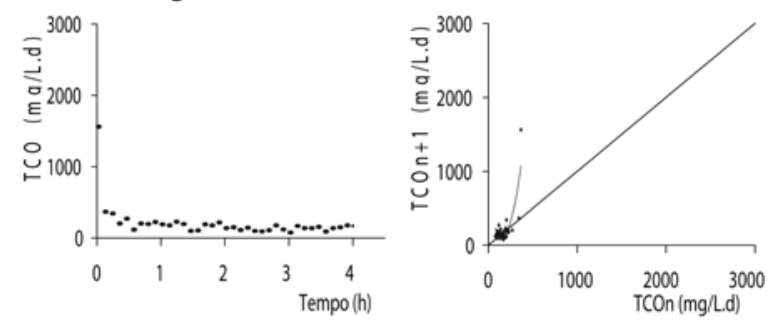

i) NONA COLETA DE DADOS
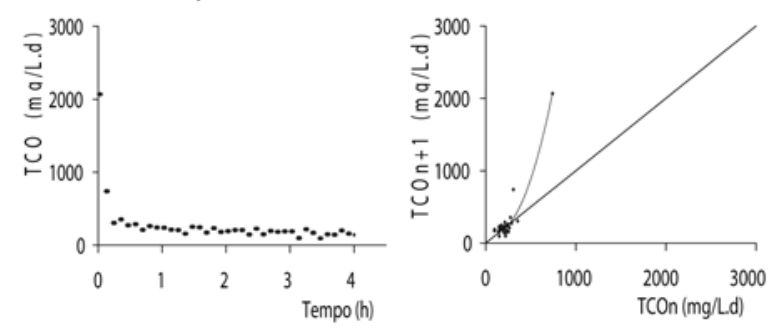

b) SEGUNDA COLETA DE DADOS
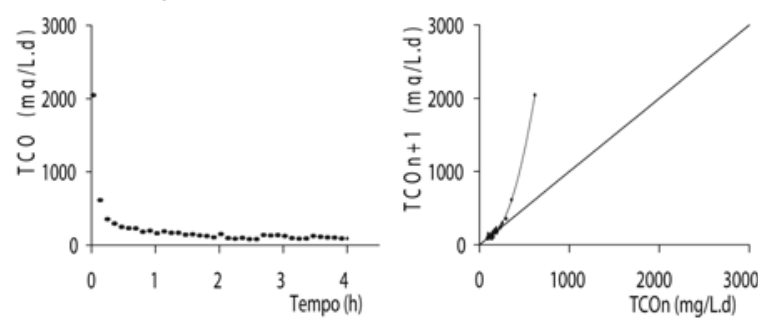

d) QUARTA COLETA DE DADOS
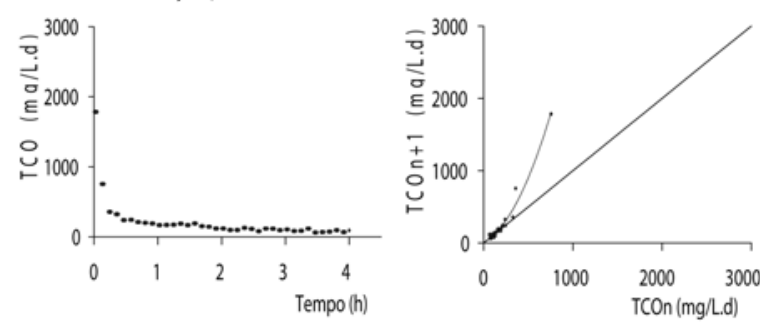

f) SEXTA COLETA DE DADOS
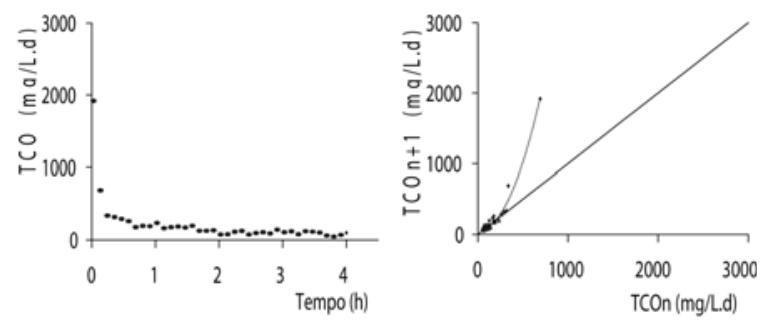

h) OITAVA COLETA DE DADOS
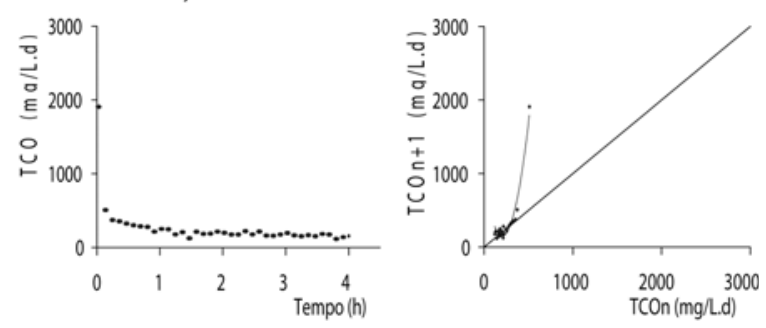

j) DÉCIMA COLETA DE DADOS
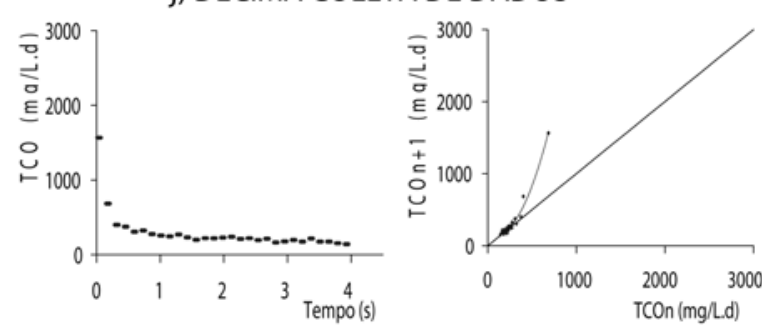

Figura 5 - Taxas de consumo de oxigênio dissolvido e gráficos de $\mathrm{TCO}_{n+1} \times \mathrm{TCO}_{n}$ obtidos na idade de lodo de 10 dias 
a) PRIMEIRA COLETA DE DADOS

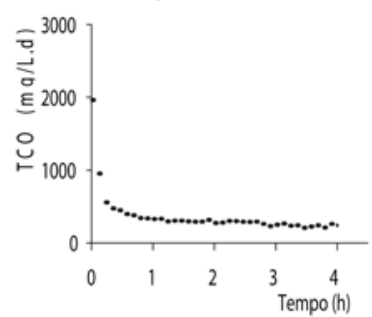

c) TERCEIRA COLETA DE DADOS

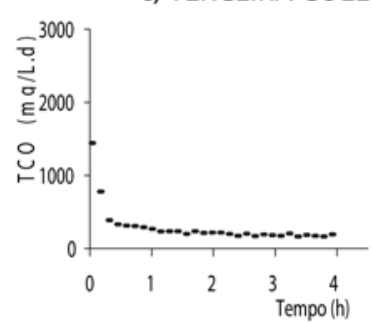

e) QUINTA COLETA DE DADOS
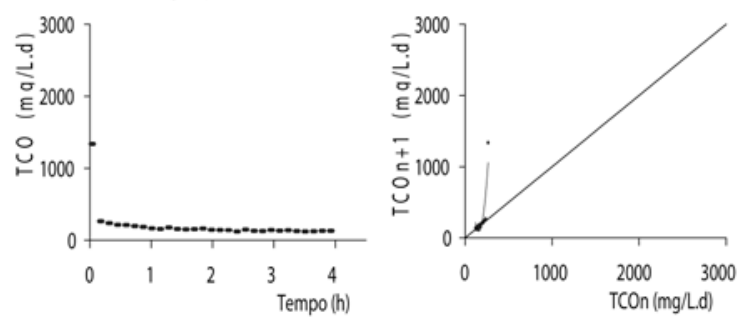

g) SÉTIMA COLETA DE DADOS
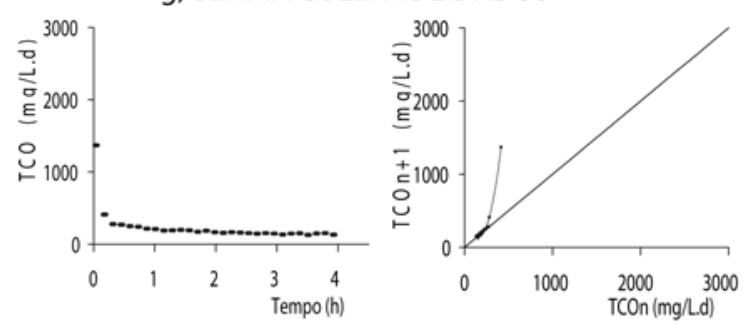

i) NONA COLETA DE DADOS
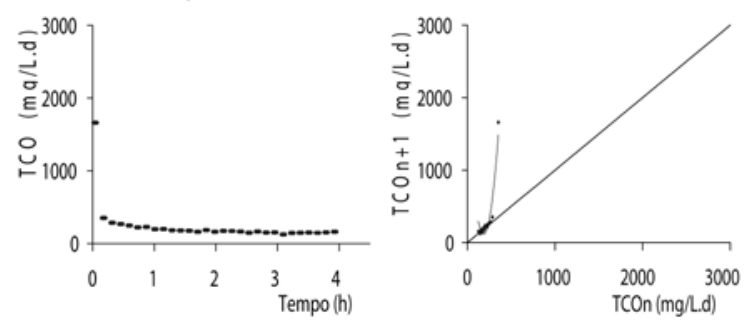

b) SEGUNDA COLETA DE DADOS
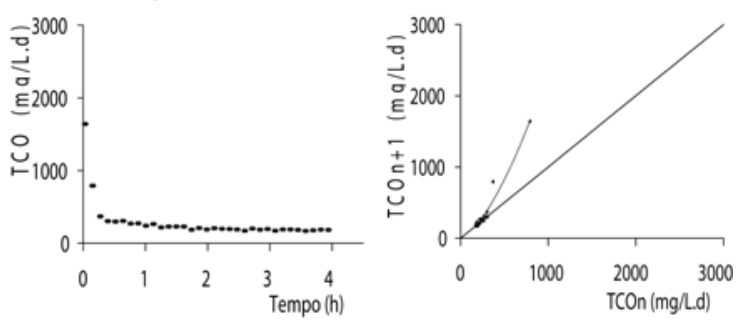

d) QUARTA COLETA DE DADOS
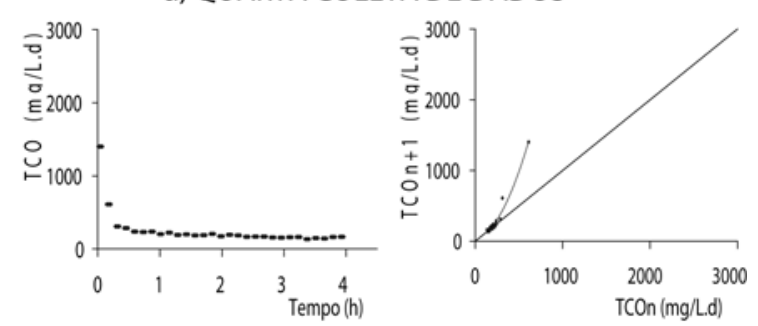

f) SEXTA COLETA DE DADOS
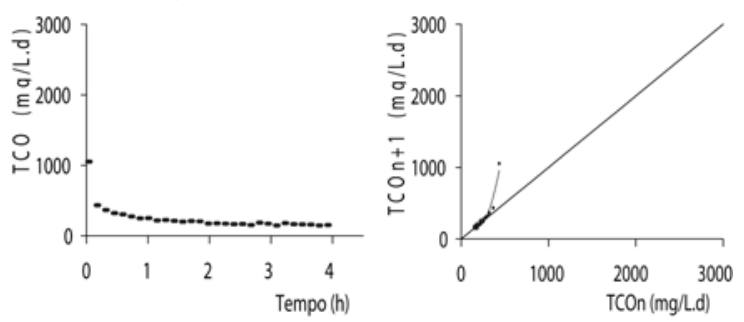

h) OITAVA COLETA DE DADOS
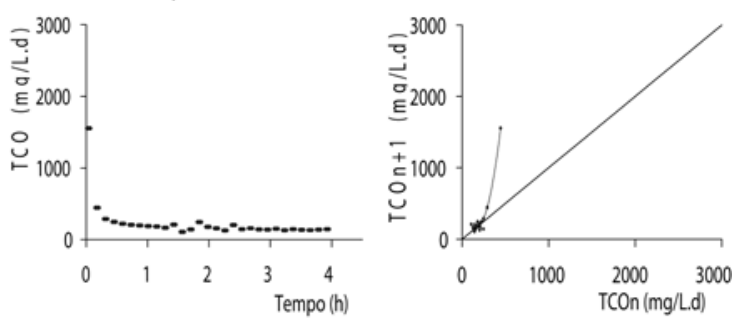

j) DÉCIMA COLETA DE DADOS
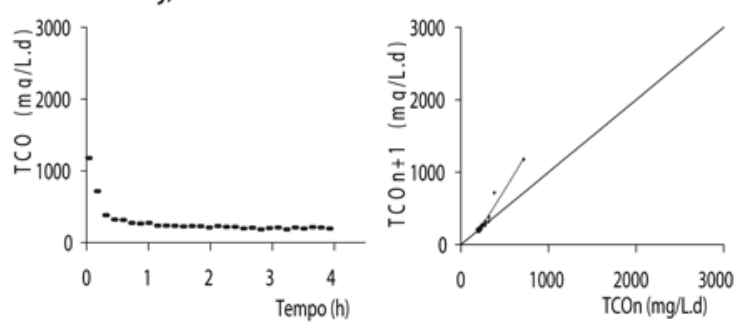

Figura 6 - Taxas de consumo de oxigênio dissolvido e gráficos de $\mathrm{TCO}_{n+1} \times \mathrm{TCO}_{n}$ obtidos na idade de lodo de 5 dias 
Tabela I - Taxa de consumo de oxigênio e tempo de aeração que caracterizam o fim da oxidação da matéria orgânica facilmente biodegradável no RSB

\begin{tabular}{|c|c|c|c|c|c|}
\hline $\begin{array}{l}\text { Idade do } \\
\text { lodo }(\mathrm{d})\end{array}$ & $\begin{array}{c}\text { TCO } \\
\text { (mg/L.d) }\end{array}$ & $\begin{array}{c}\text { Tempo } \\
\text { (h) }\end{array}$ & $\begin{array}{l}\text { Idade do } \\
\text { lodo (d) }\end{array}$ & $\begin{array}{c}\text { TCO } \\
(\mathrm{mg} / \mathrm{L} . \mathrm{d})\end{array}$ & $\begin{array}{c}\text { Tempo } \\
\text { (h) }\end{array}$ \\
\hline \multirow[t]{10}{*}{30} & 270 & 1,30 & 10 & 340 & 0,45 \\
\hline & 282 & 0,50 & & 205 & 0,95 \\
\hline & 300 & 1,00 & & 132 & 1,15 \\
\hline & 247 & 0,92 & & 115 & 1,95 \\
\hline & 296 & 0,81 & & 105 & 1,80 \\
\hline & 404 & 0,72 & & 175 & 1,26 \\
\hline & 488 & 0,67 & & 220 & 1,26 \\
\hline & 373 & 0,72 & & 290 & 0,85 \\
\hline & 396 & 0,75 & & 246 & 1,16 \\
\hline & 315 & 0,93 & & 246 & 0,95 \\
\hline Média & 337,1 & 0,83 & Média & 207,4 & 1,17 \\
\hline \multirow[t]{10}{*}{20} & 498 & 0,83 & 5 & 270 & 2,00 \\
\hline & 382 & 1,00 & & 197 & 2,00 \\
\hline & 336 & 0,61 & & 198 & 2,25 \\
\hline & 574 & 1,00 & & 172 & 2,00 \\
\hline & 329 & 0,83 & & 194 & 0,91 \\
\hline & 292 & 0,95 & & 267 & 1,00 \\
\hline & 286 & 0,75 & & 226 & 0,91 \\
\hline & 377 & 0,70 & & 227 & 1,47 \\
\hline & 270 & 0,70 & & 233 & 0,91 \\
\hline & 326 & 0,95 & & 214 & 2,00 \\
\hline Média & 367,0 & 0,83 & Média & 219,0 & 1,54 \\
\hline
\end{tabular}

As médias das taxas de consumo de oxigênio obtidas através da metodologia ora proposta foram $337,1,367,0,207,4$ e 219,0 mg/L.d para as idades do lodo de 30, 20, 10 e 5 dias, respectivamente. Para esta seqüência da idade do lodo, as médias dos tempos que definem o fim da oxidação da matéria orgânica facilmente biodegradável foram $0,83,0,83,1,17$ e 1,54 h. Os valores da TCO e do tempo indicam a influência da idade do lodo sobre o fim da oxidação da matéria orgânica facilmente biodegradável. Nas idades do lodo de 30 e 20 dias, constata-se que as médias dos tempos que indicam o término da oxidação da matéria orgânica facilmente biodegradável coincidiram. Trabalhos desenvolvidos por Santos (2005) e Santos et al (2005) na base experimental deste trabalho mostraram que o balanço de massa no RSB nas idades do lodo de 30 e 20 dias apresentaram valores semelhantes para as frações da matéria téria orgânica facilmente biodegradável mais elevada na idade do lodo de 20 dias, uma vez que a média da TCO foi mais elevada nesta idade do lodo. Observa-se que a composição do esgoto pode exercer influência direta sobre a TCO que define o fim da oxidação de compostos orgânicos de fácil degradação. Para Catunda e van Haandel (1993), a composição físico-química do esgoto doméstico exerce influência sobre a taxa de consumo de oxigênio. Os dados das idades do lodo de 10 e 5 dias são indícios de que pode haver uma relação entre TCO baixas e tempo de oxidação de compostos orgânicos de degradação lenta elevado. As médias do intervalo de tempo para oxidação da matéria orgânica facilmente biodegradável foram mais elevadas nas idades do lodo de 10 e 5 dias em relação as demais idades. A redução na concentração de lodo ativo reduz a capacidade de tratar o esgoto numa batelada com duração menor e, conseqüentemente, eleva o tempo de oxidação da fração biodegradável da matéria orgânica afluente. De acordo com Sawyer, McCarty e Parkin (2003), a taxa de consumo de oxigênio é governada pela concentração de microrganismos heterotróficos. É importante ressaltar que as médias dos tempos de reação aeróbia obtidas através do modelo ora proposto são coerentes com valores recomendados por Chernicharo e von Sperling (1993) para idade do lodo curta. A queda das TCOs médias com a redução da idade do lodo para 10 e 5 dias deve ser proveniente da variação na composição do esgoto e da redução na concentração da biomassa ativa. Dias (1982) estudando o comportamento de lodos ativados de fluxo contínuo em estado estacionário mostrou que a redução na idade do lodo implica em redução na TCO média. De acordo com van Haandel e Marais (1999), o anabolismo da biomassa prepondera sobre $\mathrm{o}$ catabolismo em idades do lodo baixas. $\mathrm{O}$ resultado deste comportamento do sistema de lodos ativados é maior produção de lodo e menor oxidação de matéria orgânica. A partir deste cenário, observa-se que não é possível desvincular a cinética dos processos biológicos do sistema de lodos ativados das características físicoquímicas do substrato e do parâmetro operacional idade do lodo. Os resultados obtidos com a aplicação do modelo matemático de equações de diferenças nãolineares possuem explicação física fundamentada no conhecimento acumulado do processo de lodos ativados. Além disso, a reprodutibilidade e a precisão dos 
dados são coerentes com o processo de determinação da TCO que consiste no ensaio de respirometria do lodo.

\section{CONCLUSÃO}

A metodologia ora apresentada estabelece critérios técnicos para determinar o tempo de reação aeróbia necessário para oxidação da matéria orgânica facilmente biodegradável. Tal metodologia introduz o conceito de equações de diferenças não-lineares no estudo da taxa de consumo de oxigênio. Aplica-se aos dados de TCOs um tratamento que exclui a variável tempo e explora a variação entre dados. A partir deste procedimento, surge da matemática aplicada o emprego de um modelo capaz de suprir a necessidade de alcançar uma análise menos alienada a experiência de alguns pesquisadores e mais pautada no estudo analítico dos dados de taxa de consumo de oxigênio dissolvido. Os valores obtidos com a aplicação do modelo de equações de diferenças não-lineares nos dados experimentais de TCO mostram a influência do parâmetro idade do lodo sobre o tempo de oxidação da matéria orgânica facilmente biodegradável. A redução no período de residência celular ocorre ao mesmo tempo em que se observa o aumento no tempo necessário para oxidação dos compostos orgânicos de fácil degradação. Além disso, constata-se a redução da TCO que caracteriza o início da oxidação da matéria orgânica de degradação lenta após o decréscimo da idade do lodo. Este comportamento era previsível em função da redução da concentração de lodo ativo com a diminuição do tempo de residência celular. Estabelecer uma relação entre TCO e o fim da oxidação da matéria orgânica de degradação fácil consiste na transformação de um problema da engenharia sanitária em problema matemático e resolvê-lo interpretando suas soluções de acordo com a cinética dos processos envolvidos. Em função deste cenário, constata-se que a metodologia apresentada veio consolidar o conhecimento teórico já acumulado sobre RSB a um modelo matemático que aborda uma técnica de aplicação fácil aos dados de TCO. A aplicação de equaçóes de diferenças não-lineares no estudo da cinética do RSB indica a necessidade de verificar a viabilidade de aplicação deste modelo em dados de TCO que envolvem oxidação de matéria orgânica e nitrogênio amoniacal. Lançar mão deste recurso é buscar otimizar o RSB, avançando em direção da automação do ciclo operacional com o mínimo de gasto com energia e o máximo de eficiência na remoção de matéria orgânica e nitrogênio.

\section{REFERÊNCIAS}

APHA, AWWA, WPCF. Standard methods for the examination of water and wastewater. $19^{\text {th }}$ edição. Washington DC: American Public Health Association, American Water Works Association, Water Pollution Control Federation, 1.193 p. 1995.

BASSANEZI, R. C. Ensino-aprendizagem com modelagem matemática: uma nova estratégia. São Paulo: Contexto, 389 p. 2002.

CATUNDA, P. F. C., VAN HAANDEL, A. C. $O$ balanço de massa do material orgânico $e$ nitrogenado em sistemas de tratamento de esgoto com lodo em suspensão. Engenharia Sanitária, v. 22, n. 4, p. 528-537, 1983.

CHERNICHARO, C. A. L., VON SPERLING, M. Consideraçôes sobre o dimensionamento de sistemas de lodos ativados de fluxo intermitente (batelada). In: $17^{\circ}$ CONGRESSO BRASILEIRO DE ENGENHARIA SANITÁRIA E AMBIENTAL, Natal. Anais. ABES, v. 2, Tomo 1, p. 19-23, 1993.
DIAS, M. A. C. Comportamento do sistema de lodo ativado sob condiçôes estacionárias em regióes tropicais. Campina Grande: Departamento de Engenharia Civil da Universidade Federal da Paraíba, (Dissertação, Mestrado em Engenharia Civil). 104 p. 1982

MARAIS, G. R., EKAMA, G. A. The activated sludge process part I - steady state behaviour. Water SA, v. 2, n. 4, p. 164-200, 1976.

SANTOS, A. V. et al. Balanço de massa no reator seqüencial em batelada (RSB) sob diferentes idades de lodo. In: $23^{\circ}$ CONGRESSO BRASILEIRO DE ENGENHARIA SANITÁRIA E AMBIENTAL, Campo Grande. Anais. ABES, 1CD. 2005.

SANTOS, A. S. Comportamento do reator seqüencial em batelada (RSB) sob estado estacionário dinâmico utilizando a idade do lodo como parâmetro de controle operacional. Porto Alegre, Instituto de Pesquisas Hidráulicas da Universidade Federal do Rio Grande do Sul, (Tese de Doutorado em Recursos Hídricos e Saneamento Ambiental) 206 p. 2005.

SAWYER, C. N.; McCARTY, P. L.; PARKIN, G. F. Chemistry for environmental engineering and science. $5^{\text {a }}$ ediçãa. McGraw-Hill: New York, 732 p. 2003.

VAN HAANDEL, A. C., MARAIS, G. V. R. O comportamento do sistema de lodo ativado: teoria e aplicações para projetos e operaçōes. Campina Grande: epgraf, 472 p. 1999.

Endereço para correspondência:
Altemar Vilas dos Santos
Centro Federal de Educação
Tecnológica da Bahia - UNED
Rua das Várzeas, $S / N^{\circ}$
47805-250 Barreiras - BA - Brasil
Tel.: (77) $9136-72 / 4$
Fax: (77) $3611-5419$
E-mail: vilarsantos@ibest.com.br

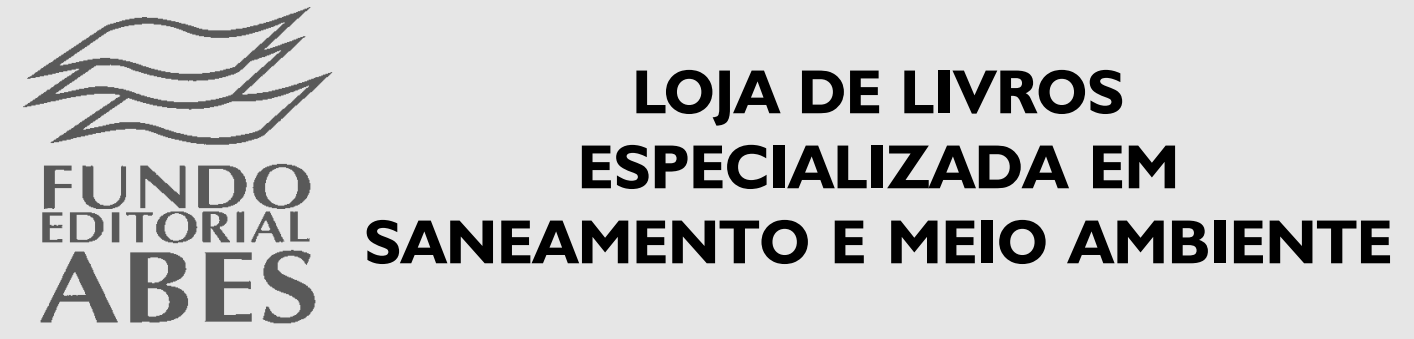

Listagem organizada por assunto e tabela de preços - www.abes-dn.org.br 